\title{
MAGNITUDE OF DIABETES MELLITUS IN PATIENTS OF SUDDEN SENSORINEURAL HEARING LOSS AND ITS EFFECT ON CORTICOSTEROID THERAPY
}

\author{
Tahira Sajid, Fatima Sajid, Zara Sajid, Syeda Rifaat Qamar Naqvi, Syed Maisam Ali, Muhammad Imran Shah \\ Ayub Medical College Abbottabad Pakistan, *Combined Military Hospital/National University of Medical Sciences (NUMS) Rawalpindi Pakistan
}

\begin{abstract}
Objective: To determine the magnitude and effects of diabetes mellitus in patients of sudden sensorineural hearing loss and on the final outcome of therapy.

Study Design: Cross sectional study.

Place and Duration of Study: ENT unit of Medical Teaching Institution Abbottabad, from Jul 2018 to Jun 2020.

Methodology: A total of 84 patients presented who had idiopathic sudden sensorineural hearing loss by using non probability consecutive sampling enrolled in the study. Basic parameters, age, diabetes mellitus and hearing loss were used for data collection. The data was analyzed by using SPSS version 23.

Results: Out of total $52(61.9 \%)$ were male and $32(38.1 \%)$ were female, mean age was $45.62 \pm 14.12$ years from 14-85 years. A large number of patients presented within one week of onset of hearing loss $57(67.86 \%)$. In our patient group 18 patients $(21.4 \%)$ had diabetes mellitus and 66 patients $(78.6 \%)$ did not have diabetes mellitus at presentation. Initial Hearing loss at presentation was significantly more in patients who had diabetes mellitus $p=0.006$ and there was statistically strong association between the final hearing improvement and diabetes mellitus $p<0.001$.

Conclusion: Diabetes mellitus is associated with more severe hearing loss at initial presentation and poorer final outcome in patients with Idiopathic sudden sensorineural hearing loss. As glycemic control does not affect the result so corticosteroid therapy must be given to all patients of sudden sensorineural hearing loss with diabetes mellitus.
\end{abstract}

Keywords: Corticosteroid therapy, Diabetes mellitus, Sudden sensorineural hearing loss.

How to Cite This Article: Sajid T, Sajid F, Sajid Z, Naqvi SRQ, Ali SM, Shah MI. Magnitude of Diabetes Mellitus in Patients of Sudden Sensorineural Hearing Loss and Its Effect on Corticosteroid Therapy. Pak Armed Forces Med J 2021; 71 (Suppl-3): S626-629. Doi: https://doi.org/10.51253/pafmj.v1i1.7109

This is an Open Access article distributed under the terms of the Creative Commons Attribution License (https://creativecommons.org/licenses/by-nc/4.0/), which permits unrestricted use, distribution, and reproduction in any medium, provided the original work is properly cited.

\section{INTRODUCTION}

Sudden sensorineural hearing loss (SSHL) is defined as a hearing loss of at least $30 \mathrm{~dB}$ over 3 contiguous test frequencies occurring within a 72 hour period. ${ }^{1-4}$ Sudden sensorineural hearing loss occurs in every 10 people out of 100,000 each year. ${ }^{1}$

The pathogenesis of sudden sensorineural hearing loss is still not fully understood. ${ }^{1}$ The postulated causes of sudden sensorineural hearing loss include viral infections, vascular abnormalities, genetic predisposition, autoimmune diseases, traumatic rupture of cochlear membrane and combined factors, but the exact cause still hasn't been established.1,3,5 Recently, diabetes mellitus is being implicated as a cause for sudden sensorineural hearing loss. ${ }^{1,6,7}$ Diabetes mellitus is a metabolic disorder due to relative or absolute lack of insulin resulting in elevated blood glucose levels associated with long term vascular and neurological complications. ${ }^{7,8}$ There are 2 types of diabetes mellitus; type 1 and type 2 . In type 1 diabetes there is inadequate synthesis of insulin by the pancreas while

Correspondence: Dr Zara Sajid, Department of ENT, Ayub Medical College Abbottabad-Pakistan in type 2 diabetes the sensitivity of cells to insulin is decreased. ${ }^{9}$

Researches show that the incidence of sudden sensorineural hearing loss in patients with diabetes mellitus increases with an increase in the severity and duration of diabetes mellitus, and also with the presence of other risk factors such as hypertension, dyslipidemia, renal disorders, obesity, smoking, alcoholism etc. ${ }^{3}$ Also the prognosis of hearing loss is worse in patients with more risk factors. ${ }^{3}$ A Study showed that the severity of hearing loss was less in patients who are using anti-diabetic medications; furthermore, most patients using both oral hypoglycemic drugs and insulin had better hearing than those who were using only oral hypoglycemic drugs. ${ }^{6}$

Steroids have been widely used in the treatment of sudden sensorineural hearing loss. In patients with diabetes mellitus the hyperglycemia induced as a result of steroids may be a limiting factor in the outcome. We are planning to calculate the magnitude of DM in patients who present to us with sudden sensorineural hearing loss and its effect on the final outcome of the steroid therapy in these patients. 


\section{METHODOLOGY}

This cross sectional study was conducted from July 2018 to June 2020 in ENT unit of Medical Teaching Institution Abbottabad. Approval from ethical review committee was taken. Sample size calculated by using WHO sample size calculator by using $95 \%$ confidence interval, 5\% error and prevalence of hearing loss was $92.6 \%$ among patients with poor control diabetes and $68.75 \%$ among those with good control diabetes. ${ }^{10}$ Calculated sample size was 40 but we took 84 patients presented who had sudden sensorineural hearing loss and they were fulfilling our criteria as below and gave informed consent to be included in our study. Nonprobability consecutive sampling technique was used. The patients who developed sensorineural hearing loss in 3 frequencies on pure tone audiometry (PTA) within 3 days without any obvious cause were selected while in cases where the cause of hearing loss was known were excluded from the study. The patients were asked in detail about the history of diabetes mellitus and were given prednisolone in the full anti-inflammatory dose of $1 \mathrm{mg} / \mathrm{kg} /$ day for 7 days. During this time, their blood sugar levels were monitored along with their blood pressure. On day 3 and then on day 7, their PTA was repeated and steroid was tapered off in the next 1 week in patients who showed full recovery, who showed no recovery and in those with fluctuating blood pressure or blood sugar levels. Low dose of steroid was continued in those patients who showed partial response till complete recovery or static response on PTA, after which it was tapered off. Both initial and final reports were recorded. In patients of SSNHL, the incidence of diabetes mellitus and its effect on the outcome of therapy was recorded and assessed.

SPSS-23 was used for data analysis. Descriptive and inferential statistics was employed. Categorical variables were analyzed in the form of frequencies and numerical variables analyzed through mean and standard deviation. Chi-square test was used. The $p$-value of $\leq 0.05$ was considered significant.

\section{RESULTS}

A total of 84 respondent were included in this study, out of total $52(61.9 \%)$ were male and $32(38.1 \%)$ were female, mean age was $45.62 \pm 14.12$ years from 14-85 years. Out of 84 patients 25 patients (29.8\%) were between $10-35$ years of age, 27 patients $(32.1 \%)$ between $36-50$ years, 29 patients (34.5\%) between $51-65$ years and 3 patients $(3.6 \%)$ above 66 years of age. A large number of patients presented within one week of onset of hearing loss 57 (67.86\%).
In our patient group 18 patients $(21.4 \%)$ had diabetes mellitus and 66 patients $(78.6 \%)$ did not have diabetes mellitus at presentation. Initial Hearing loss at presentation was significantly more in patients who had diabetes mellitus as shown in Table-II $(p=0.006)$.

\begin{tabular}{l|c}
\multicolumn{2}{l}{ Table-I: Demographic and reproductive variables. } \\
\hline Study Parameters & $\mathbf{n}(\mathbf{0})$ \\
\hline Age (Mean \pm SD) & $45.62 \pm 14.12$ years \\
\hline Age Groups & $25(29.8)$ \\
10-35 years & $27(32.1)$ \\
36-50 years & $29(34.5)$ \\
51-65 years & $3(3.6)$ \\
Above 66 years & $18(21.4)$ \\
\hline Diabetes Mellitus & $66(78.6)$ \\
\hline Yes
\end{tabular}

Table-II: Associations between diabetes mellitus and initial hearing loss.

\begin{tabular}{l|c|c|c}
\hline \multirow{2}{*}{ Hearing Loss (Hz) } & \multicolumn{2}{|c|}{ Diabetes Mellitus } & $\begin{array}{c}p \text { - } \\
\text { value }\end{array}$ \\
\cline { 2 - 3 } & Yes, (n=18) & No, (n=66) & \\
\hline Mild $40 \mathrm{~Hz}$ & $1(1.2)$ & $16(19)$ & \\
Moderates $55 \mathrm{~Hz}$ & $1(1.2)$ & $21(25)$ & \\
Mod Server $70 \mathrm{~Hz}$ & $5(6)$ & $16(19)$ & \multirow{2}{*}{0.006} \\
Severe $90 \mathrm{~Hz}$ & $4(4.8)$ & $4(4.8)$ & \\
Profound $120 \mathrm{~Hz}$ & $4(4.8)$ & $3(3.6)$ & \\
Dead Ear & $3(3.6)$ & $6(7.1)$ & \\
\hline
\end{tabular}

Table-III: Association of final hearing improvement and diabetes mellitus.

\begin{tabular}{l|c|c|c}
\hline \multirow{2}{*}{ Hearing Improvement } & \multicolumn{2}{|c|}{ Diabetes Mellitus } & \multirow{2}{*}{$\begin{array}{c}\boldsymbol{p} \text { - } \\
\text { value }\end{array}$} \\
\cline { 2 - 3 } & $\begin{array}{c}\text { Yes, } \\
(\mathbf{n = 1 8})\end{array}$ & $\begin{array}{c}\text { No } \\
(\mathbf{n}=\mathbf{6 6})\end{array}$ & \\
\hline Return to Normal & $5(27.8)$ & $49(74.2)$ & $<0.001$ \\
Hearing Hearing Loss & $13(72.2)$ & $17(25.8)$ & \\
\hline
\end{tabular}

After treatment 54 patients $(64.3 \%)$ had return to Normal Hearing while $30(35.7 \%)$ patients had some degree of persistent hearing loss show in Figure.

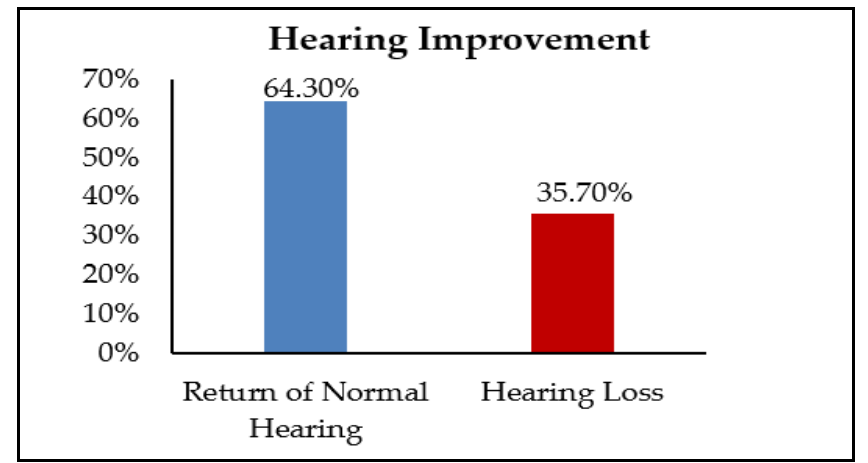

Figure: Final result of treatment in terms of return to normal hearing.

Five patients $(27.8 \%)$ with diabetes mellitus had return to normal hearing while $49(74.2 \%)$ patients with no diabetes achieved normal hearing. There was 
statistically strong association between the final hearing improvement and diabetes mellitus $p<0.001$.

\section{DISCUSSION}

Sudden sensorineural hearing loss is fortunately not very common in our community. When a patient develops sudden hearing loss it is very alarming and disturbing for that patient. If treated early there is a very good chance of complete recovery. The etiology of sudden sensorineural hearing loss is unknown. The relationship between sensorineural hearing loss and diabetes mellitus is still controversial 11 but recent studies have shown a positive correlation between the two. $8,11,12$ This correlation is established based on the neuropathic and angiopathic abnormalities that often accompany diabetes mellitus. It is speculated that the vascular and neuronal changes occurring as a result of diabetes mellitus could lead to the thickening of the basal membrane of the capillaries of stria vascularis, demyelination of the nerve of the cochlea and atrophy of spiral ganglion; all of which, alone or in combination, would lead to hearing loss. $3,9,11,13$

Other factors which have been implicated in the pathogenesis of sudden sensorineural hearing loss like viral inflammatory conditions of the labyrinth, autoimmune conditions damaging the cochlear apparatus or any degree of compromise in the blood flow due to microvascular diseases respond well to corticosteroid therapy. ${ }^{14,15}$ Systemic administration of corticosteroids has been shown to have very good efficacy especially if given early in the course of the disease as has been shown in the studies done by a number of researchers. ${ }^{4,5,14}$

We assessed the different parameters of the disease in patients who had DM as compared to the patients who were not suffering from DM at presentation to our department. It has been shown by different studies that people having DM are at increased risk of developing both progressive ${ }^{16}$ as well as sudden sensorineural hearing loss. ${ }^{12}$ We had $21.4 \%$ of the patients who had diabetes mellitus at initial presentation and the rest of the patients were normal. This is similar to a study done in Korea in which $23.3 \%$ of the patients presenting with SSNHL had DM. ${ }^{17}$ Another study done in Maryland USA in 2003 showed 23\% prevalence of DM in patients with SNHL. ${ }^{18}$

According to our results, the patients with DM presented with significantly worse hearing loss at presentation as compared to the non-diabetics. These results are the same as shown by other studies done by Seo et al, and Penido et al.,17 Another study done by
Yeo et al, also had poorer hearing threshold in patients having metabolic syndrome as compared to the normal population. ${ }^{3}$

Our results also showed that patients who had preexisting DM did not respond very well to treatment. The final outcome was also poorer in patient group who had Type II DM as a comorbidity as compared to the non-diabetic group of patients. Similar figures were shown by Rinaldi et al, in their study of patients with metabolic syndrome including DM. In their study $60 \%$ patients with metabolic syndrome showed recovery while $92 \%$ of the normal patients showed recovery. 1, two studies done in 2009 in Brazil and 2018 in Korea also showed significantly poor recovery in patients with comorbidities like DM or Hypertension. ${ }^{2,3}$

Strangely this difference in poorer outcome is not related to the glycemic control of the patients as is shown by a study done in Seoul by Min et al. ${ }^{5,19}$ But rather the duration of DM had a direct relation with the severity of hearing loss. ${ }^{19}$ This is very important because the treatment for SSNHL is corticosteroid which as a side effect causes hyperglycemia. As hyperglycemia is not associated with poorer prognosis so corticosteroids can be safely administered in patients with DM. ${ }^{5}$

\section{CONCLUSION}

Patients presenting with Idiopathic sudden sensorineural hearing loss may have diabetes mellitus as a comorbid condition. Such patients usually present with more severe hearing loss. These patients when given corticosteroid therapy have a worse outcome as compared to the non diabetic group. However, as glycemic control does not affect the results so corticosteroid therapy must be tried in all patients of idiopathic sudden sensorineural hearing loss with diabetes.

\section{Conflict of Interest: None.}

\section{Authors' Contribution}

ts: Data collection, write Up, FS: Data analysis, littreture Review, ZS: Littreture review write up, SRQN: Proof reding, SMA: Data collection, MIS: Data collection.

\section{REFERENCES}

1. Rinaldi M, Cavallaro G, Cariello M, Scialpi N, Quaranta N. Metabolic syndrome and idiopathic sudden sensori-neural hearing loss. Plos One 2020; 15(8): e0238351.

2. Penido ND, Cruz OL, Zanoni A, Inoue DP. Classification and hearing evolution of patients with sudden sensorineural hearing loss. Braz J Med Biol Res 2009; 42(8): 712-716.

3. Jung SY, Shim HS, Hah YM, Kim SH, Yeo SG. Association of metabolic syndrome with sudden sensorineural hearing loss. JAMA Otolaryngol Head Neck Surg 2018; 144(4): 308-314.

4. Ubink-Veltmaat LJ, Damoiseaux RA, Rischen RO, Groenier KH. Please, let my doctor be obese: associations between the 


\section{Sudden Sensorineural Hearing Loss}

characteristics of general practitioners and their patients with type 2 diabetes. Diabetes Care 2004; 27(10): 2560-2564.

5. Min SK, Shin JH, Chang MY, Min HJ, Kim KS, Lee SY, et al. Impact of control of blood glucose level during treatment of sudden deafness in diabetics: relationship with prognosis. Eur. Arch. Oto-Rhino-L 2017; 274(3): 1339-1343.

6. Idugboe OJ, Kolawole BA, Totyen EL. Hearing Threshold Level among Adult Diabetics in South-Western Nigeria. J Otolaryngol Rhinol 2018; 4(2): 51-55.

7. Singh A, Kour B, Dolma K. Sensorineural Hearing Loss and Type 2 Diabetes Mellitus: A clinical study. J. Med. Sci. Clin. Res 2020; 8(2): 679-682.

8. Pathak NA, Rokade VV, Shinde KJ. Screening of auditory acuity in patients with type 2 diabetes mellitus. Ind J Otol 2017; 23(2): 67-70.

9. Ghosh UC, Fakir MA, Osmany HQ, Lodh D, Islam MZ, Islam MN. Effect of Diabetes Mellitus on Hearing. Banglad J Otorhinolaryngol 2019; 25(2): 116-124.

10. Hosseini MS, Saeedi M, Khalkhali SA. Prevalence of hearing disorders among type 2 diabetes mellitus patients with and without vitamin d deficiency. Maedica J Clin Med 2020; 15(1): 3236.

11. Kim MB, Zhang Y, Chang Y, Ryu S, Choi Y, Kwon MJ, et al. Diabetes mellitus and the incidence of hearing loss: a cohort study. Int J Epidemiol 2017; 46(2): 717-726.
12. Lin SW, Lin YS, Weng SF, Chou CW. Risk of developing sudden sensorineural hearing loss in diabetic patients: a populationbased cohort Study Otol Neurotol 2012; 33(9): 1482-1488.

13. Gadag RP, Nayak PS, Tejaswini J. Clinical Asssessment of sensorineural hearing loss among diabetes mellitus patients. Bengal J Otolaryngol Head Neck Surg 2020; 28(2): 112-119.

14. Sajid T, Ali SM, Shah MI, Hussain A, Zaman A, Naqvi SR Q, et al. Oral corticosteroid therapy for sudden sensorineural hearing loss and factors affecting prognosis. J Ayub Med Coll 2021; 33(2): 279-282.

15. Xie Y, Orabi NA, Zwolan TA. Outcomes of unilateral idiopathic sudden sensorineural hearing loss: Two decades of experience. Laryngoscope Investig Otolaryngol 2019; 4(6): 693-702.

16. Dayanand A, Dheebika J, Prathula S, Palaninathan S. A study on prevalence of hearing loss as a complication of diabetes. Eur J Med Health Sci 2020; 2(4): 405-408.

17. Seo HW, Chung JH, Byun H, Jeong JH, Lee SH. Effect of diabetes on the prognosis of sudden sensorineural hearing loss: propensity score matching analysis. Otolaryngol. Head Neck Surg 2020; 162(3): 346-352.

18. Kakarlapudi V, Sawyer $R$, Staecker $H$. The effect of diabetes on sensorineural hearing loss. Otol Neurotol 2003; 24(3): 382-386.

19. Mozaffari M, Tajik A, Ariaei N, Ali Ehyaii F, Behnam H. Diabetes mellitus and sensorineural hearing loss among non-elderly people. East Mediterr Health J 2010; 16(9): 947-952. 